\title{
Estudo do potencial de Jatropha curcas L. (Euphorbiaceae) sobre o manejo da cochonilha da roseta
}

Anderson M. Holtz

Thais Coffler ${ }^{2}$

Jéssica Mayara Coffler Botti ${ }^{3}$

Mayara Loss Franzin 4

Hágabo Honorato de Paulo 5

Johnatan Jair de Paula Marchiori6

\section{Resumo}

O alto custo socioeconômico e ambiental dos agroquímicos proporcionou a busca de alternativas eficientes e ecologicamente compatíveis no controle de pragas. 0 emprego de produtos derivados de plantas torna-se uma alternativa promissora. Devido à utilização indiscriminada de produtos não registrados para o controle de Planococcus citri, objetivou-se avaliar no presente trabalho o potencial de uso de Jatropha curcas. Foram utilizados indivíduos com 10, 15, 20 e 25 dias de idade. As concentrações usadas no experimento foram 0,$0 ; 0,5 ; 1,0 ; 1,5 ; 2,0 ; 2,5$ e 3,0 \%. Na aplicação direta, empregaram-se discos de folhas de café (4 cm de diâmetro) inoculados com cochonilhas e pulverizados com auxílio da torre de Potter. Na aplicação indireta, esses foram imersos durante 5 segundos nas soluções e, em seguida, inoculadas as cochonilhas. Foram realizadas 6 repetições por concentração. $\mathrm{Na}$ aplicação direta, não houve interação entre os fatores idade do inseto, extratos das estruturas da planta e concentrações. A maior mortalidade ocorreu com indivíduos de 10 dias de idade, em óleo de pinhão manso. Na aplicação indireta, houve interação entre os fatores idade do inseto, extratos das estruturas e concentrações. Na concentração de 0,5 \%, idade de 10 dias, as maiores mortalidades foram para o óleo, extratos de casca do caule e de raiz. Resultados semelhantes foram observados nas outras concentrações, principalmente no óleo e casca do caule. Conclui-se que estruturas e óleo de pinhão manso são eficientes no manejo da cochonilha da roseta.

Palavras-chave: Controle alternativo. Planococcus citri. Jatropha curcas.

\footnotetext{
1 Instituto Federal do Espírito Santo - Campus Itapina, professor pesquisador, Colatina, Espírito Santo, Brasil.anderson.holtz@ifes.edu.br. BR 259, Km 70, Caixa Postal 256, Colatina, ES, CEP 29709-910.

2 Instituto Federal do Espírito Santo - Campus Itapina, graduanda em Agronomia, Colatina, Espírito Santo, Brasil. thais-coffler@hotmail.com. BR 259, Km 70, Caixa Postal 256, Colatina, ES, CEP 29709-910.

3 Instituto Federal do Espírito Santo - Campus Itapina, graduanda em Agronomia, Colatina, Espírito Santo, Brasil. jessicabotti@hotmail.com. BR 259, Km 70, Caixa Postal 256, Colatina, ES, CEP 29709-910.

4 Instituto Federal do Espírito Santo - Campus Itapina, graduanda em Agronomia, Colatina, Espírito Santo, Brasil. mayaralossfranzin@hotmail.com. BR 259, Km 70, Caixa Postal 256, Colatina, ES, CEP 29709-910.

5 Instituto Federal do Espírito Santo - Campus Itapina, graduando em Agronomia, Colatina, Espírito Santo, Brasil. hagabohp@hotmail.com. BR 259, Km 70, Caixa Postal 256, Colatina, ES, CEP 29709-910.

6 Instituto Federal do Espírito Santo - Campus Itapina, graduando em Agronomia, Colatina, Espírito Santo, Brasil. johnatanmarchiori@gmail.com. BR 259, Km 70, Caixa Postal 256, Colatina, ES, CEP. 29709-910.
} 


\section{Introdução}

A cultura cafeeira no Brasil sempre ocupou posição de destaque, não apenas pela importância econômica, mas também por exercer importante função social, pois é geradora de grande número de empregos, diretos e indiretos, sendo responsável pela fixação de grande parte da população na zona rural. Desde meados do século XIX, a cafeicultura é o pilar central da agricultura no estado do Espírito Santo (SCHMIDT et al., 2004).

Atualmente, almejando melhores mercados, os produtores investem na melhoria da qualidade do produto, enfrentando neste processo alguns entraves, como o controle de pragas. A cochonilha da roseta, Planococcus citri (Risso, 1813) (Hemiptera: Pseudococcidae), tem aumentado sua importância pelos prejuízos diretos à produtividade do cafeeiro conilon (FANTON et al., 2005).

Entre os métodos utilizados para controle de cochonilhas na agricultura, o químico é o mais usual e de eficiência relativa, pois para a cochonilha da roseta, por exemplo, não há, atualmente, produtos registrados para a cultura do café. Porém, o uso intensivo desses produtos, principalmente os não registrados para determinada praga, pode provocar o ressurgimento da praga-alvo, bem como o aparecimento de novas pragas, uma vez que a maioria desses produtos utilizados possui amplo espectro biológico e persistência no ambiente, prejudicando assim a saúde do consumidor e dos profissionais envolvidos nos processos de produção (BRITO et al., 2004).

Objetivando a busca de medidas alternativas ao controle químico que apresenta alto custo socioeconômico, pesquisas relacionadas à utilização de extratos e substâncias obtidos de plantas estão demonstrando uma eficiência satisfatória no controle de pragas. O Chenopodium ambrosiodes, por exemplo, apresenta substâncias com propriedades fungicidas, bactericidas, viricidas, nematicidas, inseticidas e alelopáticas (LORENZI; MATOS, 2002; VENDRAMIM, 2003; VENDRAMIM; TAVARES, 2005).

Outro exemplo de plantas inseticidas são as pimenteiras. Elas apresentam em sua estrutura uma série de amidas (a piperina, por exemplo), as quais agem como neurotoxinas e afetam as funções do sistema nervoso central, causando rápida paralisia do inseto (SCOTT et al., 2002). A citronela, Cymbopogon winterianus (Poaceae), também apresenta óleos com propriedades repelentes, tendo como constituintes principais mais de 80 componentes, entre eles o citronelal, o geraniol e o limonemo (MAIA et al., 1998).

Para o pinhão manso Jatropha curcas L. (Euphorbiaceae), da mesma família da mamona e mandioca, as formas de ação e efeitos das substâncias com propriedades inseticidas presentes no óleo e em extratos obtidos de várias partes da planta, a exemplo de folhas e raízes, ainda são objetos de estudos (UNGARO; REGITANO NETO, 2007). Contudo, esses mesmos autores afirmam que os seus efeitos, a exemplo de outras substâncias orgânicas com propriedades toxicológicas, podem se apresentar sob diferentes formas e, provavelmente, desencadeiam-se no metabolismo provocando: inibição alimentar, repelência, ação inibitória ou supressora da oviposição, ovos inférteis, inibição do desenvolvimento de larvas, ninfas e pupas e inibição do ato do acasalamento, além de interferir em várias rotas metabólicas importantes para o metabolismo geral.

Dessa forma, com o objetivo de reduzir e/ou substituir os agrotóxicos sintéticos por produtos ecologicamente corretos, este projeto visa avaliar a potencialidade de substâncias (extratos e óleos) da espécie J. curcas quanto à sua atividade inseticida sobre $P$. citri na cultura do café. 


\section{Metodologia}

O experimento foi realizado no Instituto Federal do Espírito Santo - Campus Itapina. Foi utilizada a espécie $J$. curcas na forma de extratos e óleos da semente e de partes de sua estrutura para estudo da atividade inseticida em $P$. citri.

Criação e manutenção da Cochonilha da Roseta: adultos de $P$. citri foram coletados em campo, em plantas de café conilon e transferidos para abóbora da cultivar Jacarezinho. As abóboras foram dispostas em bandejas de plástico $(38 \mathrm{~cm} \times 38 \mathrm{~cm} \times 9 \mathrm{~cm})$. As bandejas foram acondicionadas e mantidas em salas climatizadas com temperatura de $25 \pm 5{ }^{\circ} \mathrm{C}$, umidade relativa de $70 \pm 10 \%$ e fotofase de 12 horas. Foram inoculadas, em média, 200 ninfas de P. citri por abóbora.

Confecção dos extratos vegetais: foram coletadas folhas, caule sem casca, casca do caule, casca dos frutos e raízes de pinhão manso e transferidos para estufa de secagem, onde permaneceram a $40{ }^{\circ} \mathrm{C}$ durante 72 horas. Em seguida, essas partes foram submetidas à moagem em moinho de facas para obtenção de um pó fino. As sementes de pinhão manso coletadas foram submetidas à extração do óleo mediante prensagem a frio. Foram utilizadas 0,$5 ; 1,0 ; 1,5 ; 2,0 ; 2,5 ; 3,0$ gramas de pó de cada estrutura vegetal em $100 \mathrm{ml}$ de água destilada. Após um período de 24 horas, o sobrenadante foi separado da parte sólida utilizando um funil com algodão. As concentrações de extratos aquosos e do óleo utilizadas no experimento foram de 0,0, 0,5, 1,0, 1,5, 2,0, 2,5 e 3,0 \%. Para a diluição e aplicação dos tratamentos foi utilizada água destilada e o espalhante adesivo Tween ${ }^{\circledR} 80(0,05 \%)$.

Teste de aplicação direta - foi realizado sob condições de temperatura de $25 \pm 5^{\circ} \mathrm{C}$, umidade relativa de $70 \pm 10 \%$ e fotofase de 12 horas. Cada uma das concentrações de extratos e óleo de cada estrutura vegetal de $J$. curcas foi aplicada sobre 10 indivíduos de $P$. citri, mantidos em placas de Petri (10,0 x 1,2 cm), sobre discos de folhas de café (4 cm de diâmetro). 0 disco foi fixado à placa de Petri com uma camada de $0,5 \mathrm{~cm}$ de solução de agar-agar e vaselina sólida ao redor do disco para evitar a fuga dos insetos. Os insetos utilizados no experimento foram de 10, 15, 20 e 25 dias de idade. As placas foram pulverizadas com auxílio da torre de Potter, com pressão exercida de 15 $\mathrm{lb} / \mathrm{pol}^{2}$ e volume de $6 \mathrm{ml}$ de solução por repetição. Na testemunha, foi aplicada água destilada com espalhante adesivo do tipo Tween ${ }^{\circledR} 80$ (0,05 \%). Em cada placa de Petri foi realizada uma repetição e cada tratamento teve um total de 6 repetições. Foram realizadas avaliações 24, 48 e 72 horas após as aplicações. Foi calculada a mortalidade corrigida em relação à testemunha pela fórmula de Abbott (1925). Utilizou-se do delineamento experimental inteiramente casualizado, com os tratamentos em esquema fatorial $4 \times 6 \times 6$ (idade do inseto, extratos das estruturas e concentrações, respectivamente). Logo após, os dados foram submetidos à análise de variância (ANOVA) e as médias foram comparadas pelo teste de Tukey a $5 \%$ de probabilidade, exceto o fator concentração, que foi submetido à análise de regressão, utilizando o programa R (FERREIRA; CAVALCANTI; NOGUEIRA, 2011).

Teste de aplicação indireta - esse foi realizado sob as mesmas condições do teste anterior. Porém, nesse teste os discos de folhas de café foram imersos durante 5 segundos nos diferentes tratamentos. Após, os discos foram colocados sobre papel toalha para secar o excesso da solução. Feito esse procedimento, os discos foram acondicionados nas placas de Petri, conforme descrição anterior. Foram realizadas 6 repetições por tratamento. As avaliações, os parâmetros observados e a análise estatística foram semelhantes ao teste anterior. 


\section{Resultados e discussão}

\section{Aplicação direta}

Não houve interação entre os fatores idade do inseto, extratos das estruturas da planta de pinhão manso e concentrações $\left(F_{75,720}=1,05 ; P=0,3728\right)$. Dessa forma, estudaram-se os fatoriais duplos separadamente.

Houve interação entre os fatores idade do inseto e extratos das estruturas da planta de pinhão manso $\left(F_{15,720}=12,68 ; P<0,0001\right)$. A maior mortalidade de $P$. citri entre as estruturas ocorreu com indivíduos de 10 dias de idade, sendo que o óleo de pinhão manso apresentou maior mortalidade em todas as idades da cochonilha da roseta (Tabela 1 ).

Tabela 1. Mortalidade corrigida (\%) de diferentes idades de Planococcus citri tratadas com diferentes extratos das estruturas de pinhão manso, Jatropha curcas $^{1}$.

\begin{tabular}{lccll}
\hline $\begin{array}{c}\text { Idade/ } \\
\text { Estruturas }\end{array}$ & \multicolumn{1}{c}{$\mathbf{1 0}$} & $\mathbf{1 5}$ & $\mathbf{2 0}$ & $\mathbf{2 5}$ \\
\hline Folha & $36,5 \pm 3,06 \mathrm{Abc}$ & $27,2 \pm 2,22 \mathrm{Bb}$ & $5,5 \pm 1,25 \mathrm{Cb}$ & $0,0 \pm 0,00 \mathrm{Cb}$ \\
Óleo & $78,6 \pm 3,21 \mathrm{Aa}$ & $38,9 \pm 3,01 \mathrm{Ba}$ & $20,7 \pm 3,16 \mathrm{Ca}$ & $22,7 \pm 3,00 \mathrm{Ca}$ \\
Caule & $20,4 \pm 2,32 \mathrm{Ad}$ & $27,8 \pm 2,66 \mathrm{Ab}$ & $4,7 \pm 1,38 \mathrm{Bb}$ & $5,0 \pm 1,23 \mathrm{Bb}$ \\
Casca do caule & $40,5 \pm 2,72 \mathrm{Abc}$ & $29,6 \pm 2,51 \mathrm{Bb}$ & $4,7 \pm 0,77 \mathrm{Cb}$ & $1,9 \pm 0,99 \mathrm{Cb}$ \\
Casca do fruto & $42,9 \pm 2,90 \mathrm{Ab}$ & $31,3 \pm 3,02 \mathrm{Bab}$ & $8,6 \pm 1,43 \mathrm{Cb}$ & $2,2 \pm 0,81 \mathrm{Cb}$ \\
Raiz & $32,5 \pm 2,92 \mathrm{Ac}$ & $35,9 \pm 2,94 \mathrm{Aab}$ & $7,0 \pm 1,19 \mathrm{Bb}$ & $2,4 \pm 0,62 \mathrm{Bb}$ \\
\hline
\end{tabular}

${ }^{1}$ Médias ( $\pm E P$ ) seguidas pela mesma letra maiúscula na linha e minúscula na coluna não diferem estatisticamente entre si pelo teste de Tukey a $5 \%$ de probabilidade.

Fonte: Elaboração dos autores

Houve interação entre os fatores idade do inseto e concentrações $\left(F_{15,720}=2,56 ; P=0,0010\right)$. Em todas as concentrações, observou-se que à medida que se aumenta a idade do inseto, diminui-se a mortalidade (Tabela 2). Sendo que na idade de 10 dias houve ajuste de modelo matemático. Contudo, as demais idades apresentaram médias estatisticamente iguais, não se ajustando a nenhum modelo matemático (Figura 1).

Tabela 2. Mortalidade corrigida (\%) de diferentes idades de Planococcus citri tratadas com seis extratos das estruturas de pinhão manso Jatropha curcas em diferentes concentrações ${ }^{1}$.

\begin{tabular}{ccccc}
\hline $\begin{array}{c}\text { Idade/ } \\
\text { Concentrações }\end{array}$ & $\mathbf{1 0}$ & $\mathbf{1 5}$ & $\mathbf{2 0}$ & $\mathbf{2 5}$ \\
\hline $0,5 \%$ & $31,6 \pm 3,73 \mathrm{a}$ & $29,1 \pm 2,79 \mathrm{a}$ & $7,2 \pm 1,63 \mathrm{~b}$ & $2,7 \pm 1,00 \mathrm{~b}$ \\
$1,0 \%$ & $33,8 \pm 4,11 \mathrm{a}$ & $30,6 \pm 2,48 \mathrm{a}$ & $5,3 \pm 1,19 \mathrm{~b}$ & $6,0 \pm 1,88 \mathrm{~b}$ \\
$1,5 \%$ & $41,7 \pm 3,68 \mathrm{a}$ & $30,3 \pm 2,85 \mathrm{~b}$ & $11,3 \pm 1,79 \mathrm{c}$ & $5,7 \pm 1,60 \mathrm{c}$ \\
$2,0 \%$ & $49,3 \pm 4,07 \mathrm{a}$ & $34,4 \pm 3,39 \mathrm{~b}$ & $10,2 \pm 2,60 \mathrm{c}$ & $5,5 \pm 1,96 \mathrm{c}$ \\
$2,5 \%$ & $48,6 \pm 3,98 \mathrm{a}$ & $33,1 \pm 2,79 \mathrm{~b}$ & $10,2 \pm 2,25 \mathrm{c}$ & $5,6 \pm 1,69 \mathrm{c}$ \\
$3,0 \%$ & $46,2 \pm 4,39 \mathrm{a}$ & $33,3 \pm 2,50 \mathrm{~b}$ & $6,9 \pm 1,76 \mathrm{c}$ & $8,9 \pm 2,91 \mathrm{c}$ \\
\hline
\end{tabular}

${ }^{1}$ Médias $( \pm E P)$ seguidas pela mesma letra, na linha, não diferem estatisticamente entre si pelo teste de Tukey a $5 \%$ de probabilidade.

Fonte: Elaboração dos autores 


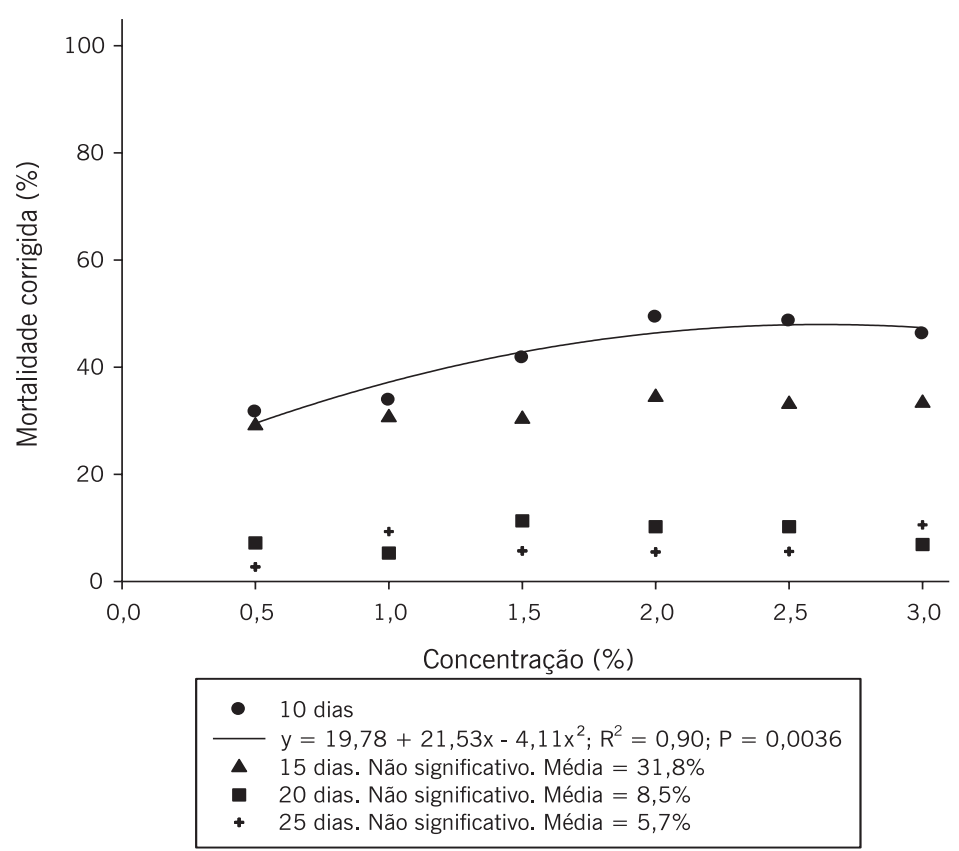

Figura 1. Mortalidade corrigida (\%) de diferentes idades de Planococcus citri tratadas com seis extratos das estruturas de pinhão-manso Jatropha curcas em diferentes concentrações.

Fonte: Elaboração dos autores

Houve interação entre os fatores extratos das estruturas da planta de pinhão manso e concentrações $\left(F_{25,720}=2,59 ; P<0,0001\right)$. Em todas as concentrações, o óleo de pinhão manso apresentou maior mortalidade de $P$. citri, com exceção de casca do caule, casco do fruto e raiz de pinhão manso nas concentrações 0,5 e 3,0 \% (Tabela 3). Houve ajuste de modelo matemático apenas para as estruturas de óleo e casca do caule, sendo que na primeira estrutura supracitada observou-se que à medida que aumenta a concentração, aumenta a mortalidade de $P$. citri (Figura 2).

Tabela 3. Mortalidade corrigida (\%) de quatro idades de Planococcus citri tratadas com diferentes extratos das estruturas de pinhão manso Jatropha curcas em diferentes concentrações

\begin{tabular}{lcccccc}
\hline $\begin{array}{c}\text { Estrutura / } \\
\text { Concentração }\end{array}$ & Folha & Óleo & Caule & $\begin{array}{c}\text { Casca do } \\
\text { caule }\end{array}$ & $\begin{array}{c}\text { Casca do } \\
\text { fruto }\end{array}$ & Raiz \\
\hline $0,5 \%$ & $12,7 \pm 3,35 \mathrm{bc}$ & $26,0 \pm 5,09 \mathrm{a}$ & $9,6 \pm 2,66 \mathrm{c}$ & $15,4 \pm 3,37 \mathrm{abc}$ & $20,1 \pm 4,10 \mathrm{abc}$ & $22,2 \pm 4,51 \mathrm{ab}$ \\
$1,0 \%$ & $15,0 \pm 3,60 \mathrm{~b}$ & $34,8 \pm 6,13 \mathrm{a}$ & $13,0 \pm 3,29 \mathrm{~b}$ & $17,2 \pm 3,77 \mathrm{~b}$ & $16,3 \pm 3,28 \mathrm{~b}$ & $17,0 \pm 3,17 \mathrm{~b}$ \\
$1,5 \%$ & $20,4 \pm 3,87 \mathrm{~b}$ & $37,0 \pm 5,87 \mathrm{a}$ & $16,5 \pm 2,77 \mathrm{~b}$ & $19,6 \pm 4,24 \mathrm{~b}$ & $17,7 \pm 3,14 \mathrm{~b}$ & $22,4 \pm 4,46 \mathrm{~b}$ \\
$2,0 \%$ & $16,5 \pm 4,21 \mathrm{~b}$ & $49,0 \pm 6,15 \mathrm{a}$ & $19,7 \pm 4,03 \mathrm{~b}$ & $21,4 \pm 4,69 \mathrm{~b}$ & $22,7 \pm 4,83 \mathrm{~b}$ & $19,8 \pm 4,82 \mathrm{~b}$ \\
$2,5 \%$ & $19,6 \pm 4,5 \mathrm{bc}$ & $43,9 \pm 5,89 \mathrm{a}$ & $15,7 \pm 3,07 \mathrm{c}$ & $19,8 \pm 3,78 \mathrm{bc}$ & $29,7 \pm 5,92 \mathrm{~b}$ & $17,5 \pm 3,56 \mathrm{c}$ \\
$3,0 \%$ & $19,5 \pm 4,00 \mathrm{~b}$ & $50,7 \pm 6,17 \mathrm{a}$ & $12,4 \pm 2,89 \mathrm{~b}$ & $21,6 \pm 4,85 \mathrm{a}$ & $21,1 \pm 4,07 \mathrm{a}$ & $17,8 \pm 3,68 \mathrm{a}$ \\
\hline
\end{tabular}

${ }^{1}$ Médias ( \pm EP) seguidas pela mesma letra, na linha, não diferem estatisticamente entre si pelo teste de Tukey a $5 \%$ de probabilidade.

Fonte: Elaboração dos autores 


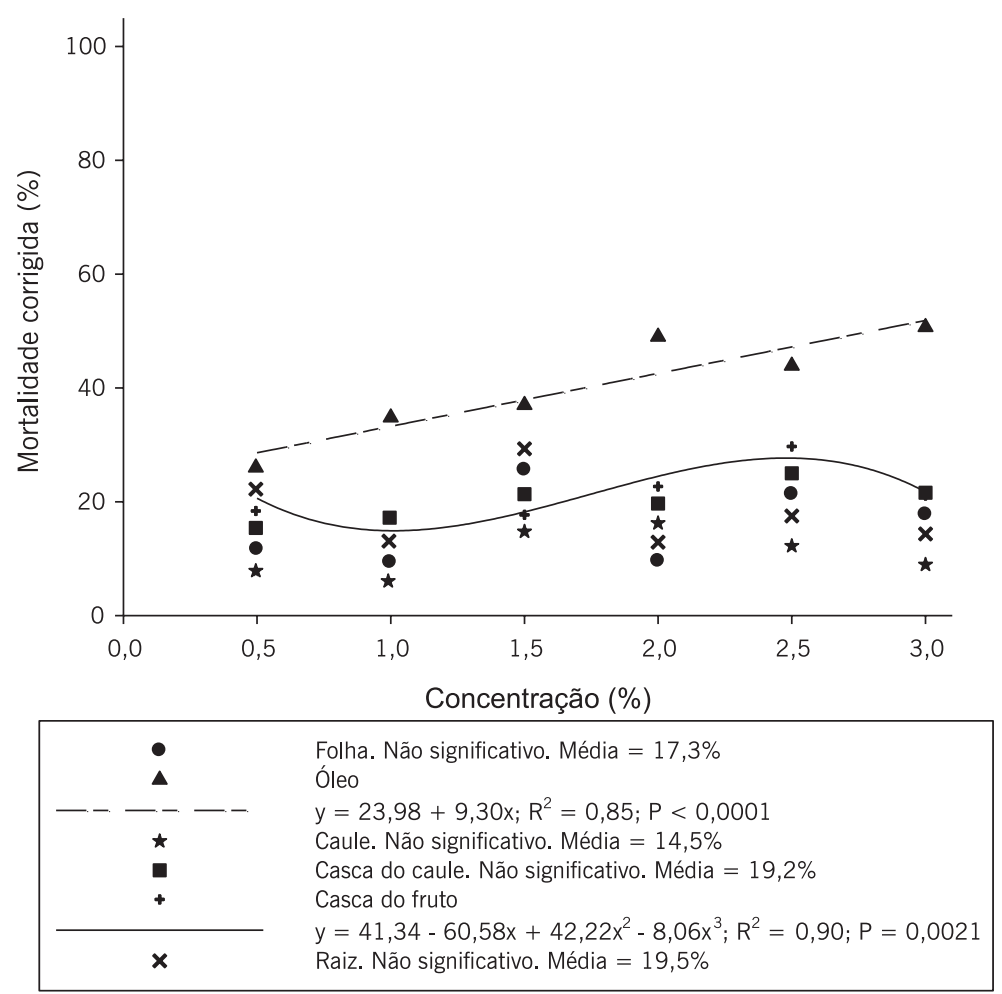

Figura 2. Mortalidade corrigida (\%) de quatro idades de Planococcus citri tratadas com diferentes extratos das estruturas de pinhão-manso Jatropha curcas em diferentes concentrações.

Fonte: Elaboração dos autores

\section{Aplicação indireta}

Houve interação entre os fatores idade do inseto, extratos das estruturas da planta de pinhão manso e concentrações $\left(F_{75,720}=3,12 ; P<0,0001\right)$. Na concentração de $0,5 \%$, idade de 10 dias, as maiores mortalidades foram para óleo, extratos de casca do caule e raiz de pinhão manso. Foram observados os mesmos resultados para as outras concentrações, principalmente para óleo e casca do caule, variando de 79 a $100 \%$ de mortalidade. Resultados semelhantes foram encontrados nas demais idades e nas diferentes concentrações. Sendo que a partir da concentração 1,0 \%, o extrato de folha também apresentou mortalidade elevada, com exceção da concentração 2,5 e 3,0 \%. Entretanto, a concentração de $2,0 \%$ do extrato do caule também apresentou mortalidade elevada da cochonilha com 15 dias de idade (Tabela 4).

Em todas as concentrações, o óleo apresentou maior mortalidade de $P$. citri nas idades de 10 e 15 dias. Sendo que o extrato da folha também apresentou mortalidade em todas as concentrações na idade de 15 dias, com exceção da concentração de 2,5\% que foi igual à idade de 10 dias, uma vez que não houve diferença estatística para 25 dias (Tabela 4).

0 extrato de casca do caule também apresentou maior mortalidade da cochonilha com idade de 10, 15 e 20 dias para as concentrações de 2,0 e 2,5\%. Contudo, o extrato do caule apresentou mortalidade elevada nas concentrações de 1,0, 1,5 e 3,0 \% na idade de 10 dias, bem como nas concentrações de 0,5 a 3,0 \% na idade de 15 dias (Tabela 4). 
Tabela 4. Mortalidade corrigida (\%) de Planococcus citri tratadas com diferentes extratos das estruturas de pinhão manso, Jatropha curcas, a diferentes concentrações e idades do inseto

\begin{tabular}{|c|c|c|c|c|}
\hline \multirow{2}{*}{$\begin{array}{c}\text { Idade/ } \\
\text { Estruturas }\end{array}$} & 10 & 15 & \multirow[t]{2}{*}{20} & \multirow[t]{2}{*}{25} \\
\hline & $0,5 \%$ & & & \\
\hline Folha & $38,7 \pm 3,62 \mathrm{Db}$ & $63,3 \pm 5,48 \mathrm{BCa}$ & $4,5 \pm 0,92 \mathrm{ABc}$ & $23,7 \pm 5,10 \mathrm{Abc}$ \\
\hline Óleo & $89,5 \pm 5,54 \mathrm{Aa}$ & $90,7 \pm 5,40 \mathrm{Aa}$ & $25,0 \pm 4,28 \mathrm{Ab}$ & $6,7 \pm 4,94 \mathrm{ABb}$ \\
\hline Caule & $61,3 \pm 6,51 \mathrm{BCb}$ & $84,0 \pm 8,95 \mathrm{ABa}$ & $0,0 \pm 0,00 \mathrm{Bc}$ & $3,3 \pm 3,33 \mathrm{ABC}$ \\
\hline Casca do caule & $96,3 \pm 3,70 \mathrm{Aa}$ & $30,2 \pm 8,89 \mathrm{Db}$ & $20,3 \pm 4,61 \mathrm{ABbc}$ & $3,5 \pm 2,6 \mathrm{ABC}$ \\
\hline Casca do fruto & $54,3 \pm 8,01 \mathrm{CDa}$ & $54,7 \pm 2,48 \mathrm{Ca}$ & $1,3 \pm 1,41 \mathrm{Bb}$ & $8,8 \pm 3,23 \mathrm{ABb}$ \\
\hline \multirow[t]{2}{*}{ Raiz } & $79,5 \pm 8,47 \mathrm{ABa}$ & $47,8 \pm 5,36 \mathrm{CDb}$ & $8,0 \pm 3,17 \mathrm{ABC}$ & $1,7 \pm 1,67 \mathrm{Bc}$ \\
\hline & $1,0 \%$ & & & \\
\hline Folha & $36,2 \pm 6,95 \mathrm{Bb}$ & $78,5 \pm 8,58 \mathrm{Aa}$ & $8,0 \pm 3,80 \mathrm{BCc}$ & $21,7 \pm 3,70 \mathrm{Abc}$ \\
\hline Óleo & $98,2 \pm 1,79 \mathrm{Aa}$ & $81,0 \pm 8,60 \mathrm{Aa}$ & $23,3 \pm 4,22 \mathrm{Bb}$ & $18,3 \pm 6,54 \mathrm{ABb}$ \\
\hline Caule & $81,3 \pm 2,68 \mathrm{Aa}$ & $70,8 \pm 4,82 \mathrm{Aa}$ & $1,7 \pm 1,67 \mathrm{Cb}$ & $0,0 \pm 0,00 \mathrm{Bb}$ \\
\hline Casca do caule & $96,2 \pm 2,47 \mathrm{Aa}$ & $46,3 \pm 7,03 \mathrm{BCb}$ & $50,7 \pm 6,42 \mathrm{Ab}$ & $4,3 \pm 2,51 \mathrm{ABCC}$ \\
\hline Casca do fruto & $47,5 \pm 8,60 \mathrm{Ba}$ & $25,2 \pm 2,81 \mathrm{Cb}$ & $2,3 \pm 1,57 \mathrm{BCc}$ & $18,2 \pm 3,96 \mathrm{ABbc}$ \\
\hline \multirow[t]{2}{*}{ Raiz } & $79,0 \pm 7,26 \mathrm{Aa}$ & $60,3 \pm 6,49 \mathrm{ABa}$ & $4,0 \pm 2,87 \mathrm{BCb}$ & $4,8 \pm 2,17 \mathrm{ABb}$ \\
\hline & $1,5 \%$ & & & \\
\hline Folha & $53,3 \pm 2,29 \mathrm{Cb}$ & $80,3 \pm 6,49 \mathrm{ABa}$ & $25,0 \pm 7,75 \mathrm{ABC}$ & $59,5 \pm 3,20 \mathrm{Ab}$ \\
\hline Óleo & $100,0 \pm 0,00 \mathrm{Aa}$ & $100,0 \pm 0,00 \mathrm{Aa}$ & $22,0 \pm 7,48 \mathrm{BCb}$ & $22,0 \pm 7,48 \mathrm{Bb}$ \\
\hline Caule & $76,8 \pm 5,89 \mathrm{Ba}$ & $62,5 \pm 9,73 \mathrm{BCa}$ & $1,7 \pm 1,67 \mathrm{Cb}$ & $3,3 \pm 2,11 \mathrm{Bb}$ \\
\hline Casca do caule & $88,2 \pm 3,09 \mathrm{ABa}$ & $53,2 \pm 3,11 \mathrm{Cb}$ & $44,0 \pm 6,08 \mathrm{Ab}$ & $12,3 \pm 5,71 \mathrm{Bc}$ \\
\hline Casca do fruto & $44,0 \pm 7,63 \mathrm{Cb}$ & $67,5 \pm 6,27 \mathrm{BCa}$ & $4,3 \pm 1,99 \mathrm{BCc}$ & $13,8 \pm 3,68 \mathrm{Bc}$ \\
\hline \multirow[t]{2}{*}{ Raiz } & $87,3 \pm 6,66 \mathrm{ABa}$ & $82,5 \pm 5,92 \mathrm{ABa}$ & $5,3 \pm 4,06 \mathrm{BCb}$ & $3,3 \pm 2,11 \mathrm{Bb}$ \\
\hline & $2,0 \%$ & & & \\
\hline Folha & $68,0 \pm 7,86 \mathrm{BCb}$ & $92,7 \pm 2,34 \mathrm{Aa}$ & $2,5 \pm 1,09 \mathrm{Cd}$ & $42,2 \pm 4,94 \mathrm{ABC}$ \\
\hline Óleo & $98,3 \pm 1,62 \mathrm{Aa}$ & $98,2 \pm 1,88 \mathrm{Aa}$ & $34,0 \pm 7,57 \mathrm{Bb}$ & $46,0 \pm 6,63 \mathrm{Ab}$ \\
\hline Caule & $66,3 \pm 3,86 \mathrm{BCb}$ & $96,3 \pm 2,23 \mathrm{Aa}$ & $1,7 \pm 1,67 \mathrm{Cc}$ & $5,0 \pm 2,24 \mathrm{Cc}$ \\
\hline Casca do caule & $91,5 \pm 4,83 \mathrm{Aa}$ & $94,8 \pm 3,57 \mathrm{Aa}$ & $90,8 \pm 4,11 \mathrm{Aa}$ & $24,7 \pm 5,71 \mathrm{ABCb}$ \\
\hline Casca do fruto & $53,8 \pm 7,65 \mathrm{Ca}$ & $58,8 \pm 8,97 \mathrm{Ba}$ & $4,0 \pm 1,83 \mathrm{Cc}$ & $24,0 \pm 5,70 \mathrm{BCb}$ \\
\hline \multirow[t]{2}{*}{ Raiz } & $80,7 \pm 7,06 \mathrm{ABa}$ & $38,2 \pm 7,52 \mathrm{Bb}$ & $5,7 \pm 1,13 \mathrm{Cc}$ & $5,0 \pm 2,24 \mathrm{Cc}$ \\
\hline & $2,5 \%$ & & & \\
\hline Folha & $68,0 \pm 5,39 \mathrm{Bab}$ & $72,5 \pm 6,24 \mathrm{Ba}$ & $26,2 \pm 7,03 \mathrm{Bc}$ & $52,3 \pm 4,16 \mathrm{Ab}$ \\
\hline Óleo & $100,0 \pm 0,00 \mathrm{Aa}$ & $100,0 \pm 0,00 \mathrm{Aa}$ & $28,3 \pm 9,46 \mathrm{Bb}$ & $11,8 \pm 4,78 \mathrm{BCb}$ \\
\hline Caule & $69,0 \pm 5,88 \mathrm{Bb}$ & $89,3 \pm 5,46 \mathrm{ABa}$ & $7,0 \pm 3,64 \mathrm{BCc}$ & $10,3 \pm 2,59 \mathrm{BCc}$ \\
\hline Casca do caule & $85,3 \pm 8,43 \mathrm{ABa}$ & $87,5 \pm 6,35 \mathrm{ABa}$ & $78,2 \pm 8,71 \mathrm{Aa}$ & $19,2 \pm 3,51 \mathrm{BCb}$ \\
\hline Casca do fruto & $44,8 \pm 3,87 \mathrm{Ca}$ & $28,8 \pm 9,45 \mathrm{Ca}$ & $1,3 \pm 1,41 \mathrm{Cb}$ & $26,3 \pm 4,44 \mathrm{Ba}$ \\
\hline \multirow[t]{2}{*}{ Raiz } & $67,8 \pm 4,25 \mathrm{Ba}$ & $43,5 \pm 6,81 \mathrm{cb}$ & $11,5 \pm 5,88 \mathrm{BCc}$ & $3,3 \pm 2,11 \mathrm{Cc}$ \\
\hline & $3,0 \%$ & & & \\
\hline Folha & $50,3 \pm 7,45 \mathrm{Db}$ & $76,2 \pm 6,02 \mathrm{Ba}$ & $12,0 \pm 5,68 \mathrm{Cc}$ & $46,0 \pm 2,89 \mathrm{Ab}$ \\
\hline Óleo & $100,0 \pm 0,00 \mathrm{Aa}$ & $100,0 \pm 0,00 \mathrm{Aa}$ & $38,3 \pm 9,10 \mathrm{Bb}$ & $36,7 \pm 7,60 \mathrm{ABb}$ \\
\hline Caule & $76,0 \pm 5,24 \mathrm{BCa}$ & $94,5 \pm 2,36 \mathrm{ABa}$ & $3,7 \pm 2,34 \mathrm{Cb}$ & $11,7 \pm 4,77 \mathrm{Cb}$ \\
\hline Casca do caule & $86,2 \pm 4,66 \mathrm{ABa}$ & $83,2 \pm 7,28 \mathrm{ABab}$ & $63,8 \pm 9,71 \mathrm{Ab}$ & $15,7 \pm 7,57 \mathrm{BCc}$ \\
\hline Casca do fruto & $62,7 \pm 8,50 \mathrm{CDa}$ & $41,7 \pm 9,93 \mathrm{Cb}$ & $5,8 \pm 3,03 \mathrm{Cc}$ & $16,2 \pm 5,19 \mathrm{BCc}$ \\
\hline Raiz & $67,5 \pm 5,87 \mathrm{BCDa}$ & $47,7 \pm 5,75 \mathrm{Cb}$ & $24,7 \pm 5,06 \mathrm{BCc}$ & $4,8 \pm 2,17 \mathrm{Cd}$ \\
\hline
\end{tabular}

Cada grupo de seis médias ( $\pm \mathrm{EP}$ ) seguidas pela mesma letra maiúscula, na coluna, não diferem estatisticamente entre si pelo teste de Tukey a $5 \%$ de probabilidade;

Médias ( \pm EP) seguidas pela mesma letra minúscula, na linha, não diferem estatisticamente entre si pelo teste de Tukey a $5 \%$ de probabilidade.

Fonte: Elaboração dos autores

Para as cochonilhas de 10 dias de idade, à medida que se aumenta a concentração, aumenta a mortalidade. Porém, para o extrato da folha, a mortalidade diminui. As demais estruturas não obtiveram modelo matemático, ou seja, as concentrações são estatisticamente iguais (Figura 3). 


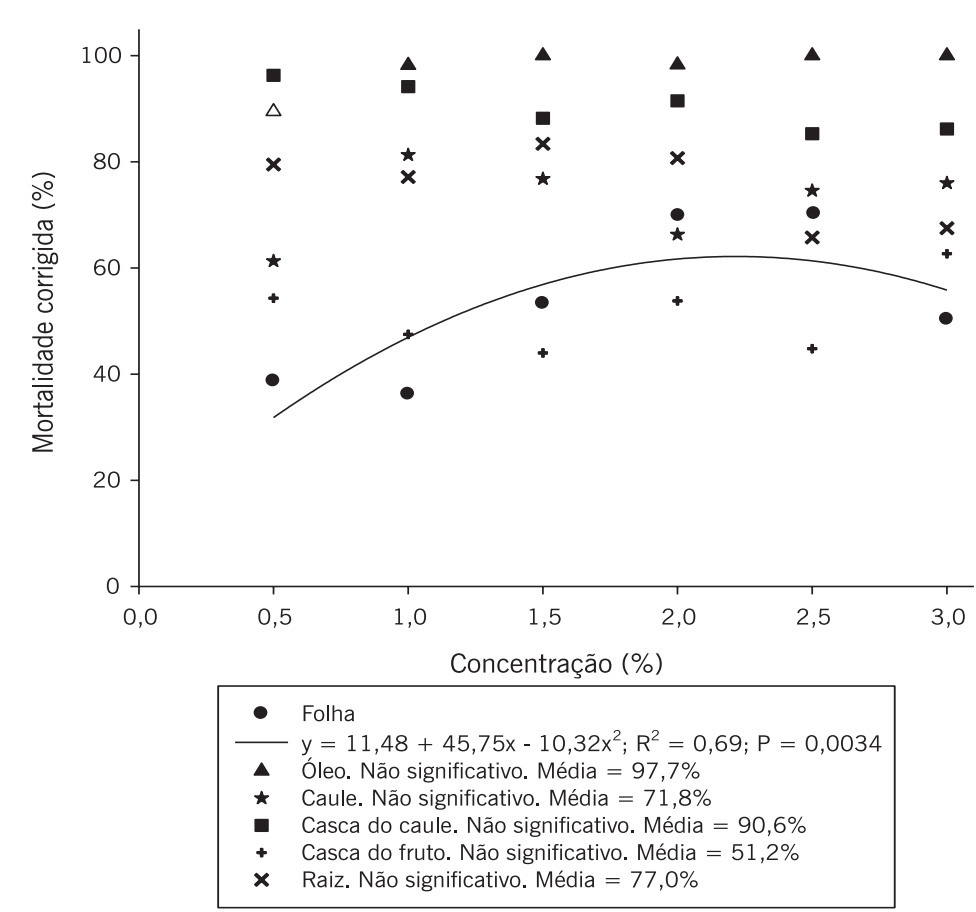

Figura 3. Mortalidade corrigida (\%) de Planococcus citri com 10 dias de vida tratadas com diferentes extratos das estruturas de pinhão manso Jatropha curcas em diferentes concentrações.

Fonte: Elaboração dos autores

Observou-se também que a mortalidade de $P$. citri com 15 dias de idade aumenta à medida que aumentam as concentrações nas estruturas casca do caule e caule (Figura 4).

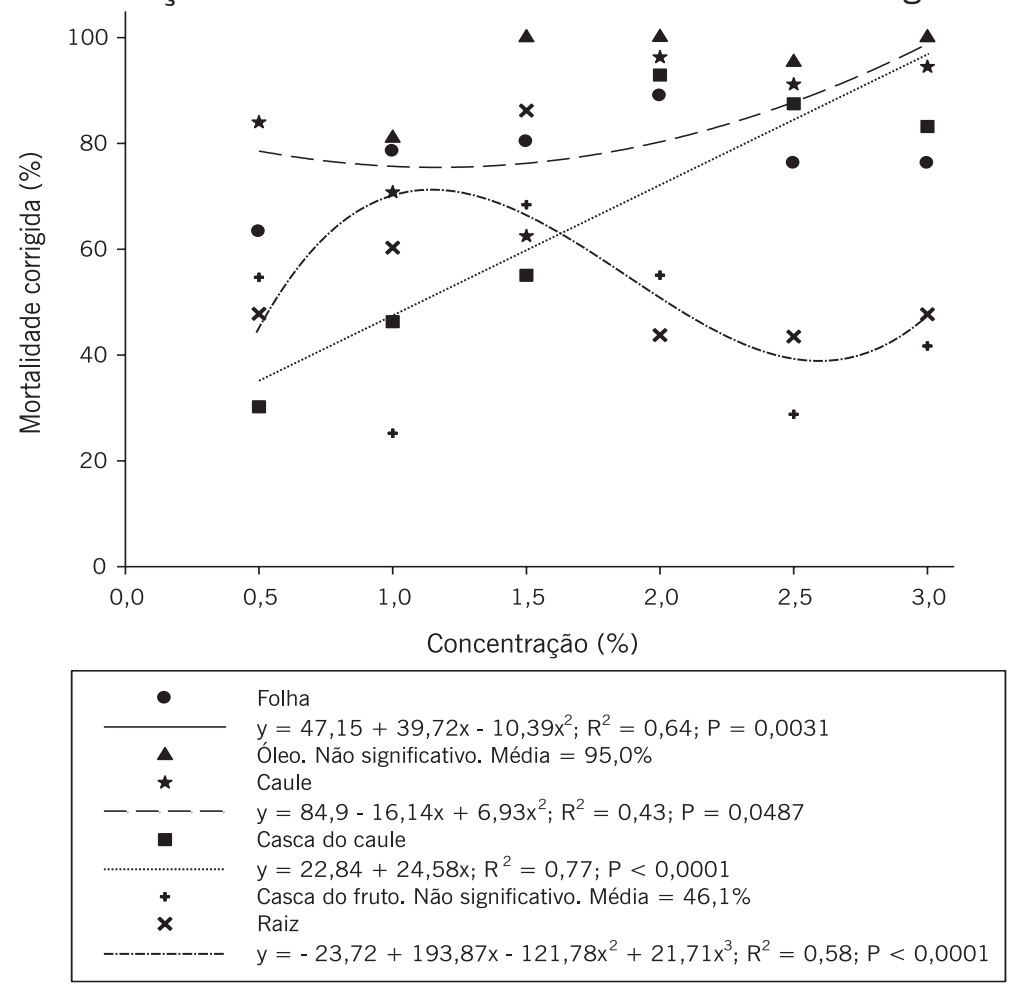

Figura 4. Mortalidade corrigida (\%) de Planococcus citri com 15 dias de vida tratadas com diferentes extratos das estruturas de pinhão manso Jatropha curcas em diferentes concentrações.

Fonte: Elaboração dos autores 
Entretanto, observando os resultados, à medida que aumenta a idade dos indivíduos, diminui a mortalidade em todas as concentrações, com exceção da casca do caule nas concentrações de 2,0 e 2,5\% na idade de 20 dias. Da mesma forma, à medida que aumenta a concentração, aumenta a mortalidade, sendo que a partir de uma determinada concentração a mortalidade diminui, isso para a idade de 20 dias com extrato da casca do caule. No entanto, as demais estruturas não tiveram diferença estatística entre as concentrações, não tendo assim modelo matemático (Figura 5).

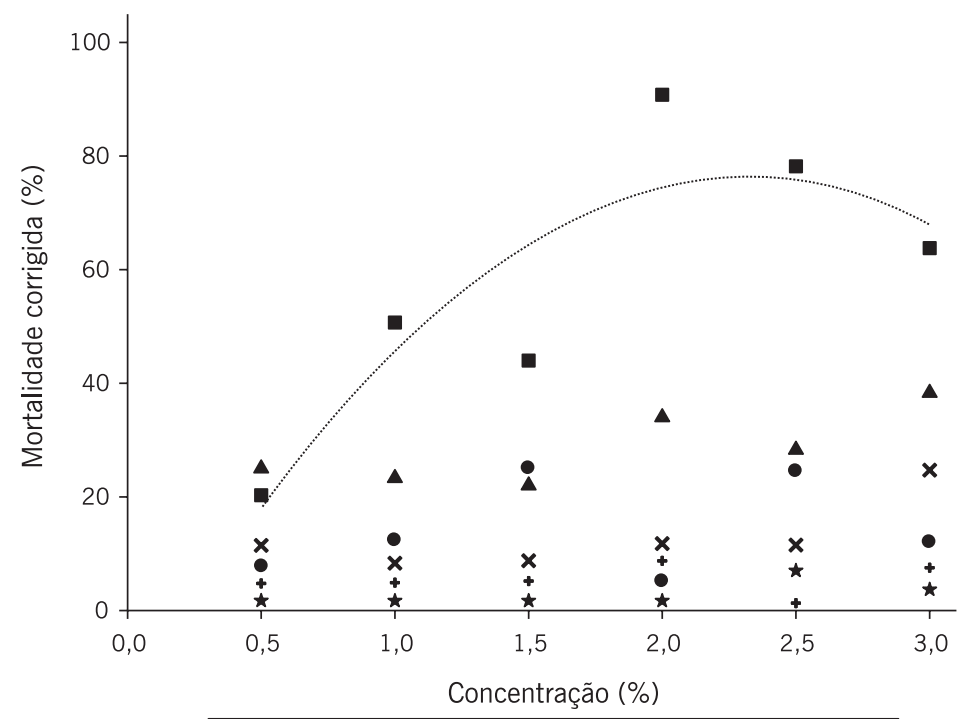

- Folha. Não significativo. Média $=13,0 \%$

- Óleo. Não significativo. Média $=28,5 \%$

$\star \quad$ Caule. Não significativo. Média $=2,6 \%$

- Casca do caule

$y=-17,93+81,65 x-17,67 x^{2} ; R^{2}=0,76 ; P<0,0001$

+ Casca do fruto. Não significativo. Média $=3,2 \%$

× Raiz. Não significativo. Média $=9,9 \%$

Figura 5. Mortalidade corrigida (\%) de Planococcus citri com 20 dias de vida tratadas com diferentes extratos das estruturas de pinhão manso Jatropha curcas em diferentes concentrações.

Fonte: Elaboração dos autores

À medida que aumenta a concentração, aumenta a mortalidade para as estruturas folha, óleo e casca do caule das cochonilhas com 25 dias. As demais estruturas obtiveram médias estatisticamente iguais (Figura 6). 


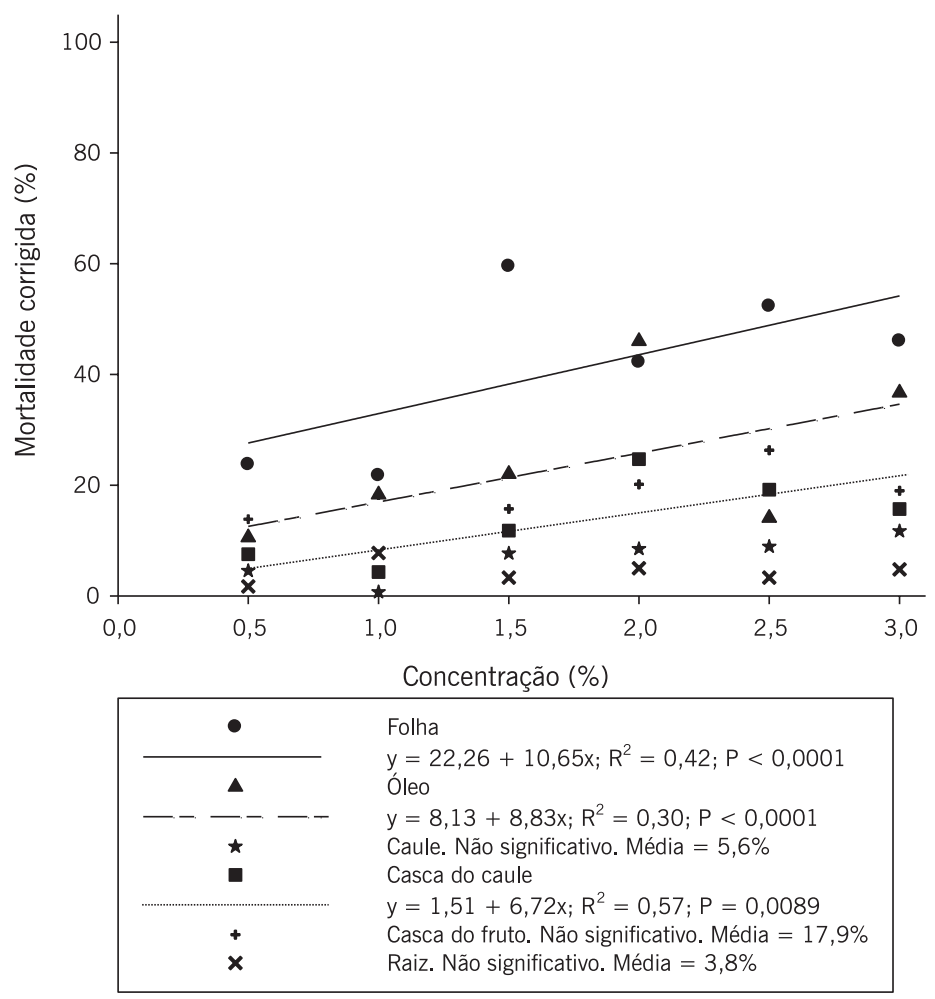

Figura 6. Mortalidade corrigida (\%) de Planococcus citri com 25 dias de vida tratadas com diferentes extratos das estruturas de pinhão manso Jatropha curcas em diferentes concentrações.

Fonte: Elaboração dos autores

A toxicidade de J. curcas é atribuída principalmente à presença de dois componentes nas sementes: uma proteína inativadora de ribossomos (curcina) e a ésteres diterpenos. A curcina é similar à ricina, uma proteína tóxica isolada de sementes de mamona (Ricinus communis), que apresenta duas cadeias polipeptídicas, uma com função de lectina e outra capaz de inibir a síntese proteica (STIRPE et al., 1976). Sendo assim, como a curcina (extraída do pinhão manso) é similar à ricina (extraída da mamona), a mortalidade do $P$. citri, provavelmente, está associada à ação conjunta de efeitos antialimentares e inseticidas de proteínas (BASHIR et al., 1998; DARBY et al., 2001) contidos no óleo extraído da semente de J. curcas. Essa atividade antialimentar é devida à ação de inibidores proteicos de $\alpha$-amilase que impedem a digestão e absorção do amido pelos insetos (OLSNES; KOZLOV, 2001). Por outro lado, a atividade inseticida é devida à ação de proteínas inativadoras de ribossomos $\left(\mathrm{RIP}_{\mathrm{S}}\right)$, que quando ingeridas provocam a morte das células dos aparelhos gastrintestinais (LORD et al., 1994; AUDI et al., 2005).

No teste de aplicação direta, a ação do óleo e dos extratos de pinhão manso sobre a cochonilha podem atuar de diferentes formas, podendo penetrar no organismo por ingestão (pelo aparelho digestivo) e por contato, atravessando o tegumento e através das vias respiratórias.

Entretanto, alguns autores argumentam que a ação por contato é mais rápida do que o modo de ação por ingestão, pois esse último para agir sobre o organismo-alvo depende do processo de digestão para incorporação e ação nos sistemas vitais da praga (KATHRINA; ANTONIO, 2004; AGUIARMENEZES, 2005; ISMAN, 2006).

Entretanto, a ação por contato do óleo de pinhão manso, possivelmente, age no sistema nervoso central do inseto, impedindo a transmissão dos impulsos nervosos, devido à inibição da enzima acetil colinesterase ou por distúrbios na acetilcolina, ou no GABA e/ou nos canais de $\mathrm{Na}^{+}$e $\mathrm{K}^{+}$. Essas 
também poderiam afetar a respiração celular, impedindo o transporte de elétrons e/ou inibidores da síntese de ATP. Em face disso, fica evidente que novas pesquisas devem ser desenvolvidas a fim de esclarecer melhor como realmente atuam tais substâncias.

\section{Conclusão}

Conclui-se que a planta de pinhão manso, nas suas diferentes estruturas, tem potencial no manejo da cochonilha da roseta e na cultura do café. $\mathrm{O}$ óleo e a folha apresentaram maior valor de mortalidade dos indivíduos $P$. citri. Contudo, estudos em condições de semicampo e campo são necessários para validar o uso em programas de manejo fitossanitário.

\section{Agradecimentos}

Ao Instituto Federal do Espírito Santo (IFES), à Fundação de Amparo à Pesquisa do Espírito Santo (FAPES) e ao Conselho Nacional de Desenvolvimento Cientifico e Tecnológico (CNPq) pelo apoio e concessão de bolsas.

\section{Abstract}

The high socio-economic and environmental costs of agrochemicals encouraged the search for efficient and environmentally compatible alternatives in pest control. The use of products derived from plants has become a promising alternative. Due to the indiscriminate use of products not registered for the control of Planococcus citri, this study aimed to evaluate the potential use of Jatropha curcas. Individuals were 10, 15, 20 and 25 days old. The concentrations used in the experiment were $0.0 ; 0.5 ; 1.0 ; 1.5 ; 2.0 ; 2.5$ and $3.0 \%$. In direct application, coffee leaf disks (4 $\mathrm{cm}$ diameter) were used, inoculated with cochineal and sprayed with the aid of a Potter's tower. In indirect application, the Planococcus citri was immersed in the solutions for 5 seconds and then the cochineal was inoculated. They were submitted to six repetitions per concentration. In the direct application, there was no interaction among the insect age factors, extracts of plant structures and concentrations. Mortality was higher in 10 days old individuals on J. curcas oil. In the indirect application, there was no interaction among the insect age factors, structures extracts and concentrations. At the $0.5 \%$ concentration, for the 10 days old individuals, the mortality was higher for oil, stem bark and root extracts. Similar results were observed in other concentrations, especially in the oil and stem bark. The study concludes that structures and J. curcas oil are effective in the management of the rosette cochineal.

Keywords: Planococcus citri. Jatropha curcas. Alternative control.

\section{Referências}

ABBOTT, W. S. A method for computing the effectiveness of an insecticide. Journal of Invertebrate Pathology, v. 18, p. 265-267, 1925.

AGUIAR-MENEZES, E. L. A. Inseticidas Botânicos: seus princípios ativos, modo de ação e uso agrícola. Seropédica: Embrapa Agrobiologia, 2005. 
AUDI, J.; BELSON, M.; PATEL, M.; SCHIER, J. Ricin poisoning: a comprehensive review. JAMA, Chicago, v. 294, p. 2342-2351, 2005.

BASHIR, M. E. H.; M. E. H.; HUBATSCH,I.;LEINENBAC H.P.; ZEPPEZAUER, M.; PANZANI, R.C.; HUSSEIN, I.H. Ricin C 1 and Ricin c 3, the allergenic 2S albumin storage proteins of ricinus communis: complete primary structures and phylogenetic relationship. International Archives of Allergy and Immunology, Milwaukee, v. 115, p. 73-82, 1998.

BRITO, G. G.; COSTA, E. C.; MAZIERO, H.; BRITO, A. B.; DÖRR, F. A. Preferência da broca-das-cucurbitáceas [Diaphania nitidalis Cramer, 1782 (Lepidoptera: Pyralidae)] por cultivares de pepineiro em ambiente protegido. Ciência Rural, Santa Maria, v. 34, p. 577-579, 2004.

DARBY, S. M.; MILLER, M. L.; ALLEN, R. O. Forensic determination of ricin and the alkaloid marker ricinine from castor bean extracts. Journal of Forensic Sciences, Colorado Springs, v. 46, p. 10331042. 2001.

FANTON, C. J.; PERINI, J. L.; GOMES, W. R.; ZUCATELI, F.; OLIVEIRA, A.; CASAGRANDE, R. P.; FORNAZIER, M. J. Guia do cafeicultor: técnicos alertam sobre a broca-do-café. COOABRIEL - órgão informativo da cooperativa de São Gabriel da Palha - ES. 2005.

FERREIRA, E. B.; CAVALCANTI, P. P.; NOGUEIRA, D. A. Experimental Designs: um pacote R para análise de experimentos. Revista da Estatística da UFOP, Ouro Preto, v. 1, p. 1-9, 2011.

ISMAN, M. B. Botanical insecticides, deterrents, and repellents in modern agriculture and an increasingly regulated world. Annual Review of Entomology, Palo Alto, v. 51, p. 45-66. 2006.

KATHRINA, G. A.; ANTONIO, L. P. J. Control biológico de insectos mediante extractos botánicos, p. 137-160. In: CARBALLO, M.; GUAHARAY, F. (Ed.). Control biológico de plagas agrícolas. Managua: CATIE, 378p, 2004.

LORD, M. J.; ROBERTS, L. M.; ROBERTUS, J. D. Ricin: structure, mode of action and some current applications. The Faseb Jounal, Bethesda, v. 8, p. 201-208. 1994.

LORENZI, H.; MATOS, F. J. A. Plantas medicinais do Brasil: nativas e exóticas. Nova Odessa: Instituto Plantarum de Estudos da Flora Ltda, 2002. 462p.

MAIA, N. B.; BOVI, O. A.; DUARTE, F. R.; CALHEIROS, M. B. P. Citronela-de-Java (Cymbopogon nardus Rend). In: . Instruções Agrícolas para as Principais Culturas Econômicas. Campinas, Instituto Agronômico. 6. ed. Campinas. Boletim 200, 1998. p. 11.

OLSNES, S.; KOZLOV, J. Ricin. Toxicon, Atlantic City, v. 39, p. 1723-1728, 2001.

SCHMIDT, H. C.; et al. Cadeia produtiva do café arábica da agricultura familiar no Espírito Santo. Vitória: Incaper, 2004. 52p.

SCOTT, I. M.; PUNIANI, E.; DURST, T.; PHELPS, D.; MERALI, S.; ASSABGUI, R. A.; SANCHEZ-VINDAS, P.; POVEDA, L.; PHILOGENE, B. J.; ARNASON, J.T.Insecticidal activity of piper tuberculatum Jacq. Extracts: synergistic interaction of piperamides. Agriculture Forest Entomology, v. 4, p. 137 144, 2002. 
STIRPE, F.; PESSION-BRIZZI, A.; LORENZONI, E.; STROCCHI, P.; MONTANARO, L.; SPERTI, S. Studies on the proteins from the seeds of Croton tigliumi and of Jatropha curcas. Toxic properties and inhibition of protein synthesis in vitro. Biochemical Journal, v. 156, p. 1-6, 1976.

UNGARO, M. R. G.; REGITANO NETO, A. Considerações sobre pragas e doenças de pinhão manso no estado de São Paulo. In: CONGRESSO BRASILEIRO DE PLANTAS OLEAGINOSAS, ÓLEOS, GORDURAS E BIODIESEL - "BIODIESEL: COMBUSTÍVEL ECOLÓGICO”, 4., 2007, Lavras. Resumos... Lavras: UFLA, 2007. 272p.

VENDRAMIM, J. D.; PROCÓPIO, S. O.; RIBEIRO JR., J. I.; SANTOS, J. B. Bioatividade de diversos pós de origem vegetal em relação a Sitophilus zeamais Mots. (Coleoptera: Curculionidae). Ciência e Agrotecnologia, Lavras, v. 27, p. 1231-1236, 2003.

VENDRAMIM, J. D.; TAVARES, M. A. G. C. Atividade insenticida da erva-de-santa-maria Chenopodium ambrosioides L. (Chenopodiaceae) em relação a Sitophilus zeamais Mots. 1855 (Coleoptera: Curculionidae). Arquivos do Instituto Biológico, São Paulo, v. 72, p. 51-55, 2005.

\section{Histórico editorial}

Submetido em: 06/05/2015

Aceito em: 29/07/2015 